\title{
Posterior Pole of the Eye
}

National Cancer Institute

\section{Source}

National Cancer Institute. Posterior Pole of the Eye. NCI Thesaurus. Code C142303.

The scleral curvature of the eye comprising the retina, inclusive of the macula and optic disc. 